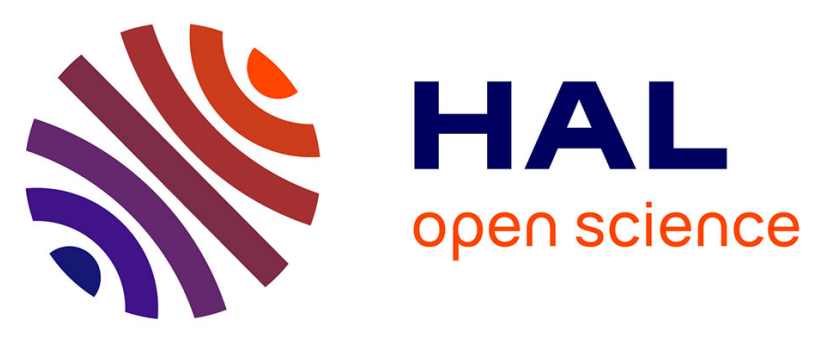

\title{
Development and Application of a Multifunctional Nanoindenter: Coupling to Electrical Measurements and Integration In-Situ in a Scanning Electron Microscope
}

S. Comby-Dassonneville, F. Charlot, R. Martin, F. Roussel-Dherbey, L. Maniguet, D. Pellerin, F. Volpi, C. Boujrouf, G. Parry, M. Braccini, et al.

\section{To cite this version:}

S. Comby-Dassonneville, F. Charlot, R. Martin, F. Roussel-Dherbey, L. Maniguet, et al.. Development and Application of a Multifunctional Nanoindenter: Coupling to Electrical Measurements and Integration In-Situ in a Scanning Electron Microscope. 2019 IEEE Holm Conference on Electrical Contacts, Sep 2019, Milwaukee, United States. pp.1-8, 10.1109/HOLM.2019.8923946 . hal-02992870

\author{
HAL Id: hal-02992870 \\ https://hal.science/hal-02992870
}

Submitted on 13 Nov 2020

HAL is a multi-disciplinary open access archive for the deposit and dissemination of scientific research documents, whether they are published or not. The documents may come from teaching and research institutions in France or abroad, or from public or private research centers.
L'archive ouverte pluridisciplinaire HAL, est destinée au dépôt et à la diffusion de documents scientifiques de niveau recherche, publiés ou non, émanant des établissements d'enseignement et de recherche français ou étrangers, des laboratoires publics ou privés. 


\section{Development and application of a multifunctional nanoindenter: coupling to electrical measurements and integration in-situ in a scanning electron microscope}

\author{
S. Comby-Dassonneville, F. Volpi, \\ C. Boujrouf, G. Parry, M. Braccini, \\ S. Iruela, A. Antoni-Zdziobeka, \\ Y. Champion, M. Verdier
}

Univ. Grenoble Alpes, CNRS Grenoble INP

SIMaP

38000 Grenoble, France

fabien.volpi@grenoble-inp.fr

\author{
F. Charlot, R. Martin, \\ F. Roussel-Dherbey, L. Maniguet \\ Univ. Grenoble Alpes, Grenoble INP \\ CMTC \\ 38000 Grenoble \\ frederic.charlot@cmtc.grenoble-inp.fr
}

D. Pellerin

Scientec / CSInstruments

91940 Les Ulis

d.pellerin@scientec.fr

\section{Abstract}

Fundamental understanding and quantitative characterization of electron transport mechanisms between two solids brought into mechanical contact require the development of a dedicated multifunctional device. In this study, we report original measurements and analysis based on a nanoindenter coupled with fine electrical measurements in-situ a Scanning Electron Microscope (SEM). After a description of the experimental set-up, we report quantitative results on resistive-nanoindentation on metallic systems with increasing complexity. Starting from a model case (Au single crystal), a procedure is developed and further applied to a complex rheology structure $(200 \mathrm{~nm} \mathrm{Au}$ thin film plastically deformed against an elastic substrate) to demonstrate the quantitative monitoring of contact area. Then a two-phase AgPdCu alloy is used to illustrate the resolution of spatial mapping of both mechanical properties and electrical resistance. Finally, we present our experimental results on natively-oxidized Al single crystal. The resistance evolutions during indentation are discussed in terms on dielectric breakdown and electrochemical processes.

Keywords-Electrical contact, nanoindentation, scanning electron microscope, area monitoring, oxide cracking, breakdown

\section{INTRODUCTION}

The understanding and the quantitative analysis of the electro-mechanical processes involved at the interface between two solids are of crucial interest for both academic and applied purposes [1,2]: electric connectors for electrotechnics and automotive applications, intermittent contacts in mechanical switches (at both macro- and micro-scales), microelectronics,... The development of scanning probe microscopy (SPM) triggered the experimental study of these phenomena at small-scale $[3,4,5]$, but only the coupling of electrical measurements with instrumented indentation (independent load and displacement measurements) provided the precise control and monitoring of both contact mechanics and electrical conduction [6]. Initiated by the monitoring of phase transformation under pressure $[7,8,9]$, resistive- indentation has then been extended to the study of other phenomena: native oxide fracture [10,11,12,13], MEMS operation at small scales [14,15] and contact area computation during nanoindentation tests $[16,17]$. In the past decades, numerous efforts have been made to further expand the capabilities of nanoindentation [6]: real-time imaging $[18,19]$, coupling with multifunctional characterisation tools $[20,21]$, high temperature measurements [22],...

The present article reports the development and the application of a home-made multifunctional characterisation device based on a commercial nanoindentation head. This device combines mechanical and electrical characterisations, and can be integrated insitu in a Scanning Electron Microscope (SEM). Quantitative electrical characterisations cover resistive and capacitive measurements (focus is made on resistive measurements in this paper). In-situ SEM integration allows precise positioning of local nanoindentation tests (with a precision better than $100 \mathrm{~nm}$ ) as well as the positioning of electrically-coupled nanoindentation maps.

\section{EXPERIMENTAL DETAILS}

The experimental set-up combines different commercial instruments, with customized adapter systems. Fig. 1 presents the Infra-Red view of the set-up once integrated within the SEM chamber.

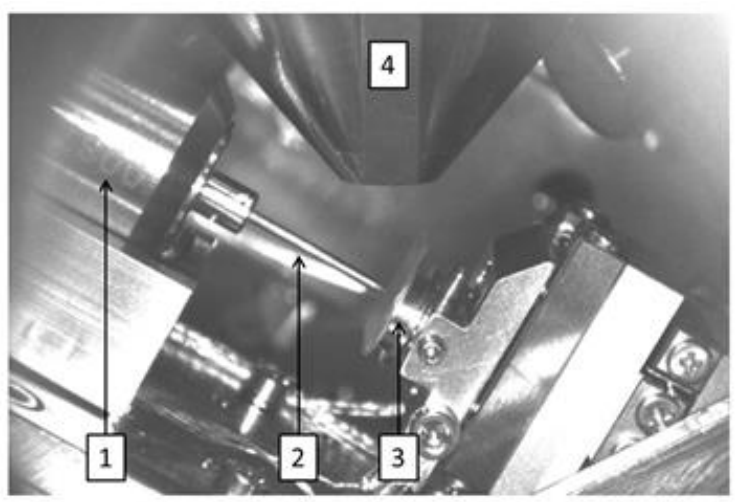

Fig. 1. Infra-Red view of the set-up once integrated within the SEM. $(1=$ Nanoindenter head, $2=$ Extender + tip, $3=$ Specimen, $4=\mathrm{SEM}$ column) 
The nanoindentation head is a commercial actuator (InForce 50 actuator from Nanomechanics Inc / KLATencor), displaying a maximum load of $50 \mathrm{mN}$ and a static load resolution below $0.1 \mu \mathrm{N}$. This force-controlled actuator enables continuous stiffness measurement (CSM) through locked-in detection of displacements induced by oscillatory loads superimposed to the main load signal. This CSM mode gives access to the continuous extraction of both hardness and elastic modulus during indentation [23]. A fast mapping technique is also available, allowing high-speed nanoindentation tests $(\sim 1$ indent per second). The indentation tip is screwed on a $1.5 \mathrm{~cm}$-long extension. All the experiments presented in this paper have been performed with boron-doped diamond (BDD) tips with resistivity in the range of [0.2-2] $\Omega . \mathrm{cm}$ (with either Berkovich, cube-corner or flat-punch shapes). Electrical contacts to the tip are made with thin copper wires connected to fixed sockets. Actuator and sample displacements are performed with linear positioners from SmarAct GmbH. Typical travel ranges are at the cm-scale with a $\sim 1 \mathrm{~nm}$ resolution. An overall stiffness larger than $10^{6} \mathrm{~N} / \mathrm{m}$ has been extracted, thus validating the overall mechanical behavior.

The SEM apparatus used was a Field Emission Gun (FEG) GEMINI SEM 500 from Zeiss [24]. The arrangement of the analytical tools within the SEM chamber has been optimized to improve the observation angle during indentations. In standard conditions, the specimen surface was scanned under a $60^{\circ}$ tilt angle, that was softwarecorrected during experiments. The SEM-integration allows positioning of indents with a precision better than $100 \mathrm{~nm}$. As an illustration, Fig. 2(a) presents a $1 \mu \mathrm{m}$-large gold island (obtained by dewetting of a gold film on sapphire substrate) after a 'smiley pattern' obtained from three indents.

Resistance measurements are conducted with a ResiScope apparatus from CSI/Scientec. Originally developed for conductive-atomic force microscopy [25], this device is optimised for real-time and self-compliant resistance measurements. It ranges from $100 \Omega$ to $1 \mathrm{~T} \Omega$, with acquisition rates up to $1 \mathrm{kHz}$. The high resistance sensitivity is illustrated in Fig. 2(b) with a typical $1 \mathrm{kHz}$ monitoring of contact resistance during indentation: the figure inset zooms in on the resistance oscillations induced by the CSM mode at $100 \mathrm{~Hz}$. These resistance oscillations correspond to contact area variations of $0.3 \%$, confirming the high sensitivity of the apparatus.

\section{RESISTIVE-NANOINDENTATION ON METALS}

\section{A. Contact area monitoring}

The real-time monitoring of resistance during nanoindentation is of particular interest for the quantitative analysis of nanoindentation tests. Indeed, the simultaneous computation of sample Young's modulus and hardness relies on a precise knowledge of the contact area $A_{c}$. However even for the simplest cases of homogeneous semi-infinite specimens, the determination of $A_{c}$ is strongly affected by pile-up or sink-in phenomena that occur at the contact periphery (Fig. 3). The actual contact area may then be misinterpreted by $20-30 \%$. The standard methods widely used to extract contact area require analytical models based on material rheology assumptions [26,27]. On the contrary, the direct monitoring of contact area by resistive-nanoindentation should bring supplementary inputs for the quantitative analysis of indentation tests. Some attempts to combine micro- or nano-indentation to resistive measurements to quantitatively analyze the indentation process have been reported $[16,17]$ but the monitoring of contact area was not processed.
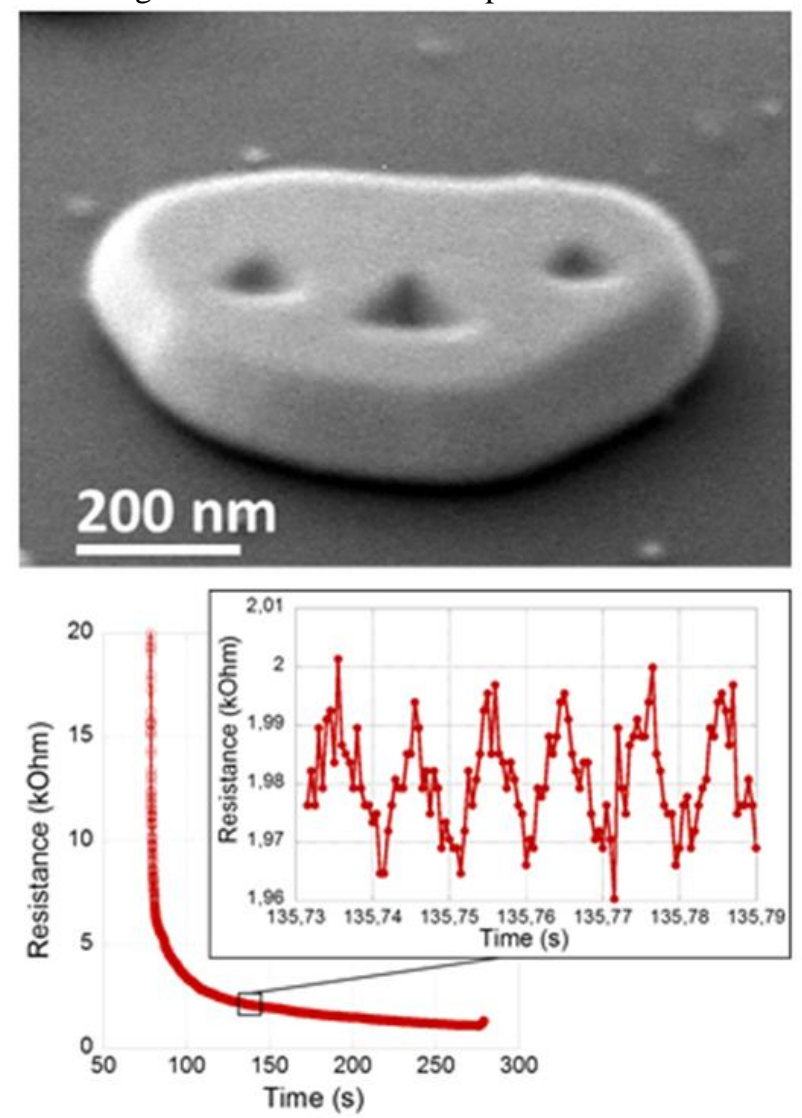

Fig. 2. Illustrations of the set-up performances. (a) Gold island after three individual indents (without tilt-correction). (b) Typical resistancevs-time curve during nanoindentation

Typical resistance-versus-depth curves obtained on a gold bulk specimen are shown in Fig. 4. As expected, resistance continuously decreases as the mechanical contact area increases [17]. It can be seen that the resistance does not depend on the applied voltage, thus evidencing an Ohmiclike electrical contact.

One of the bottleneck steps for the quantitative analysis of resistive-nanoindentation tests is the appropriate analytical description of the electrical measurement chain. In the case where the indenting tip is much more resistive than the specimen (typical case of a metal being indented with a doped-diamond tip), the measured resistance is essentially due to the tip contribution. Under this condition (and if the specimen is oxide-free), the resistance of the overall set-up can be simply given by (1) (for more details, see [28]):

$$
R_{\text {measured }}=A+B /\left(h_{c}+h_{0}\right)
$$

$A$ and $B$ are two constants that depend only on the experimental set-up (tip geometry and resistivity, series resistance,...) but not on the specimen ( $A$ and $B$ have to be determined experimentally during the calibration step, see below). $h_{0}$ is the length of the tip defect (unavoidable rounded apex of the tip). 

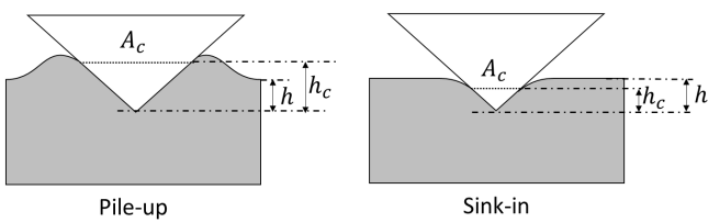

Fig. 3. Effect of material rheology on contact area and contact depth. The penetration depth $h$ is the depth reached by the tip from the initial specimen surface, while the contact depth $h_{c}$ describes the length of the tip in contact with the specimen.

This description being established, the experimental extraction of the contact area can be processed through a 3-step procedure:

- Step 1: The tip geometry is determined from direct AFM characterisation. This step generates the tip "shape function" that relates the projected contact area to the contact depth $h_{c}$.

- Step 2: An electrical calibration is carried out (on a gold bulk single crystal for instance), aiming at the determination of the $A$ and $B$ constants (see (1)). As $A$ and $B$ depend only on the experimental set-up, a one-toone analytical correspondence is then established between the electrical resistance and the contact depth (independently of the specimen).

- Step 3: The contact area monitoring of any oxide-free specimen can then be performed. Using the shape function (step 1), the contact area is finally determined from the contact depth values (step 2) for this specimen to be characterized.

This procedure has been applied and validated on a $200 \mathrm{~nm}$-thick polycrystalline gold film deposited on a sapphire substrate. Such a composite geometry is a model case of complex rheology which is depth-dependent and where no analytical model exists. To do so, resistivenanoindentation tests with various final penetration depths have been performed. For each test, post-mortem AFM measurements have been conducted to compare the contact area to the one monitored by our procedure. Fig. 5 compares those data, and shows an excellent agreement between our predictions and the effective areas. For comparison, the contact area computed from the standard Oliver-Pharr method [26] (based on sink-in assumption) is also reported showing a $\sim 50 \%$ discrepancy. Such a precise monitoring of the tip-to-sample contact area has been reported for the first time in literature in [28].

\section{B. Ballistic and diffusive conductive regimes}

It is also interesting to note that the high sensitivity of both the indentation column and the ResiScope module allows the direct observation of the transition from ballistic to diffusive conductive regimes at the very first steps of nanoindentation. In order to highlight this point, a set of nanoindentation tests is shown in Fig. 6 (only 5 tests are plotted for clarity). Two trends are clearly observed, with a transition circa $3.5 \mathrm{~nm}$. Beyond this point, the resistance evolves as the reciprocal of the penetration depth (see (1)), which is the signature of a diffusive regime. Below this transition depth, a slope discontinuity is observed, toward a power-law dependence.

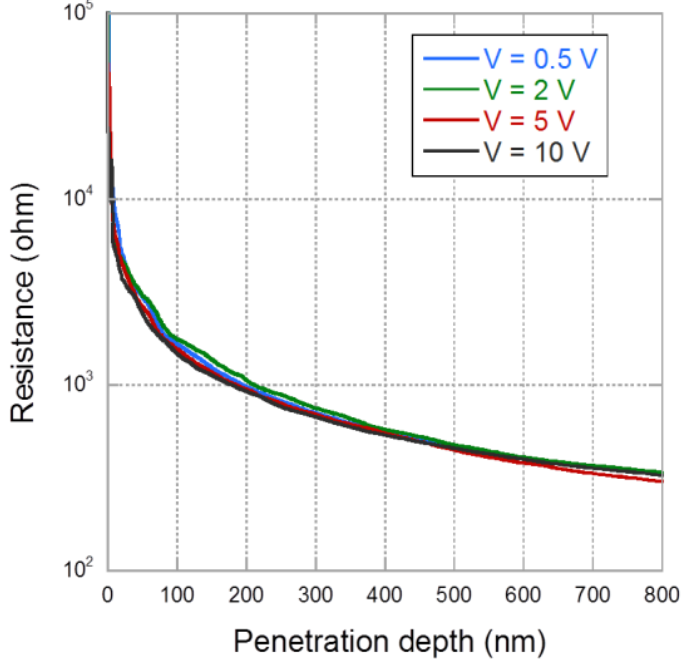

Fig. 4. Resistance-vs-depth curves for bulk Au nanoindentation with a doped-diamond Berkovich tip under different polarizations.

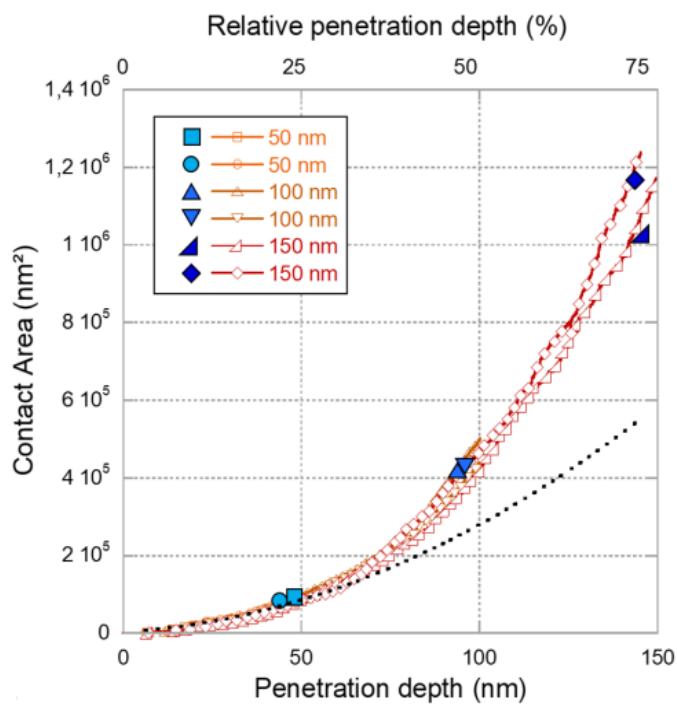

Fig. 5. Contact area against penetration depth on the $\mathrm{Au}$ thin film. Comparison of the computed data (open markers) with the corresponding post-mortem AFM measurements (solid markers). Predicted contact area from Oliver and Pharr model in dotted line.

This nm-scale transition depth may be attributed to the combination of several mechanisms:

- Sharvin condition: When the contact radius is comparable to the electron mean free path, the lateral restriction imposed to the electrical current leads to a ballistic transport regime. In that case, the electrical contact conductance evolves as a power-law of contact radius [29,1]. In the present case, the mean free path of electrons in this highly-doped diamond tip is estimated to be circa $2 \mathrm{~nm}[30,31,32]$, which is in good agreement with the present transition depth.

- Multi- $\alpha$-spots model: Based on Holm's approach [1], it has been shown that if a macroscopic contact is the combination of a large number of local spots (because of roughness, surface contamination, native oxide,...), the total contact conductance is the sum of the individual conductances with an additional term accounting for the spot interaction. It has been shown that this approach also deviates from the simple diffusive model [33]. 
- Intermittent contact: Before the mechanical contact is continuously established, the intrinsic nanoindenter vibrations (1.7 $\mathrm{nm}$ standard deviation in our system) may also lead to intermittent local contacts.

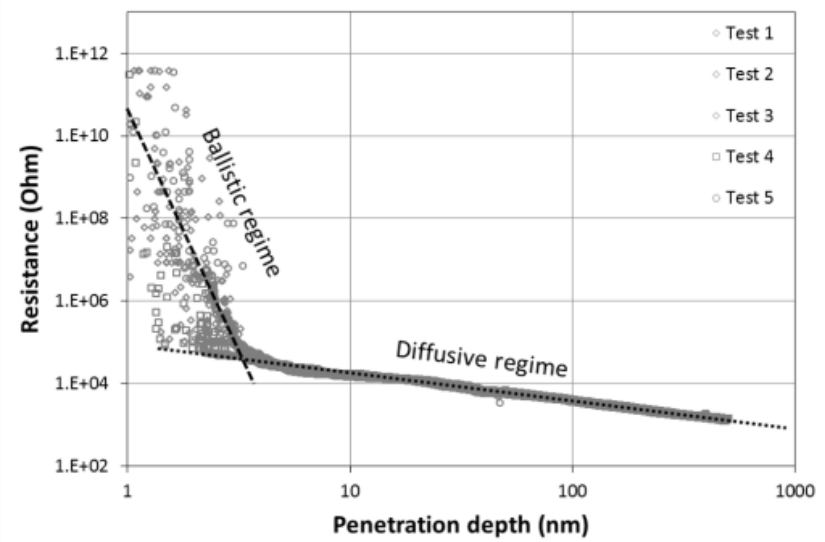

Fig. 6. Resistance-vs-depth curves for bulk $\mathrm{Au}$ nanoindentation with a doped-diamond Berkovich tip, in log-log scale.

\section{Electrical and mechanical properties: local characterisation and mapping}

As already mentioned, the integration of this resistivenanoindentation set-up within the SEM allows precise positioning of the spot to analyze as well as the electromechanical mapping of a specimen surface. These two advantages are illustrated through the study of an $\mathrm{AgPdCu}$ alloy designed to combine high conductivity and large yield strength. The composition was chosen within the miscibility gap of this ternary alloy [34,35] and annealed for $890 \mathrm{~h}$. Three phases were identified by X-Ray diffraction (Fig. 7): one phase is Ag-rich while two are $\mathrm{Cu}-$ rich (B2 and A1 crystal lattice structures). The Ag- and $\mathrm{Cu}$-rich phases can be distinguished clearly by SEM (Fig. 8): the Ag-rich phase appears as the lightest domains while the two $\mathrm{Cu}$-rich phases appear as a unique continuous dark domain (the B2 and A1 crystal structures cannot be discriminated). Fig. 8 presents an SEM view of the sample after a local indent performed on the Ag-rich phase (lightest domain).

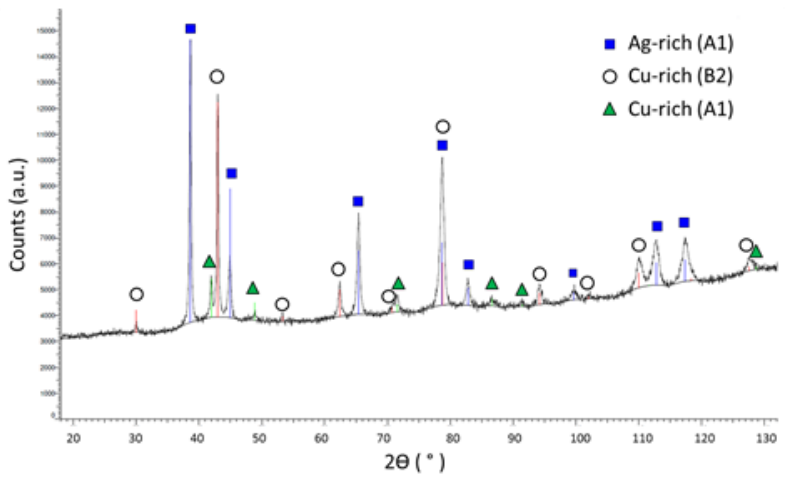

Fig. 7. $\theta-2 \theta$ X-Ray diffractogram of the $\mathrm{AgPdCu}$ alloy. Performed with $\mathrm{K} \alpha \mathrm{Cu}$ source.

Fig. 9 (a)-(b) collect the resistance and hardness measures obtained over 28 indents on the two domains. The $\mathrm{Cu}$-rich domain appears as more conductive than the Ag-rich one, but it also appears as harder. The higher resistance of the
Ag-rich domain can be attributed either to a larger intrinsic resistivity, to a more resistive native-oxide or to different material rheologies. However the data dispersion (on hardness and resistance) requires a more statistical approach, which can be fulfilled by a large-scale mapping applied to a region of interest. Fig. 10 reports such a combined mapping of contact resistance, elastic modulus and hardness measured simultaneously over a $120 \times 120 \mu \mathrm{m}^{2}$ area. This map first confirms the trend observed from the individual local characterisations, but also allows a clear correlation between harder and more conductive domains.

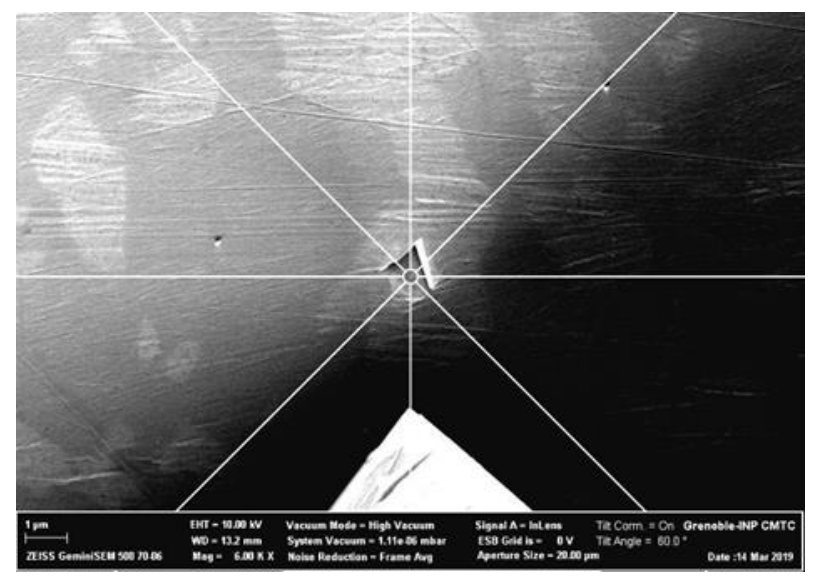

Fig. 8. SEM view of an indent left after local testing of the Ag-rich phase. The white triangle at the bottom of the image is the indenter tip.

(a)

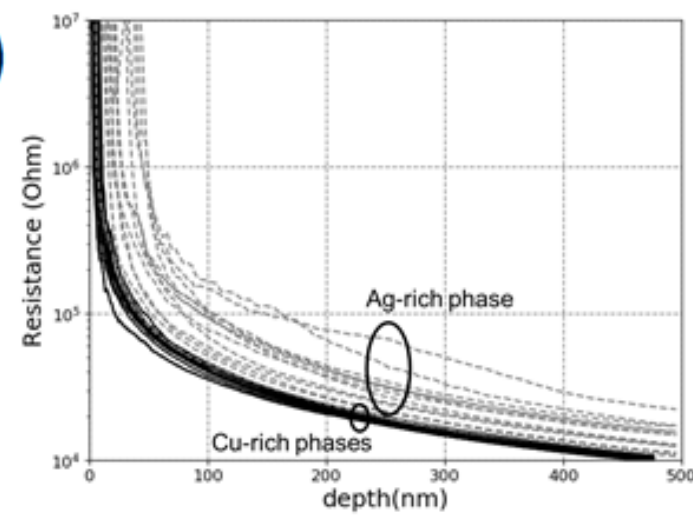

(b)

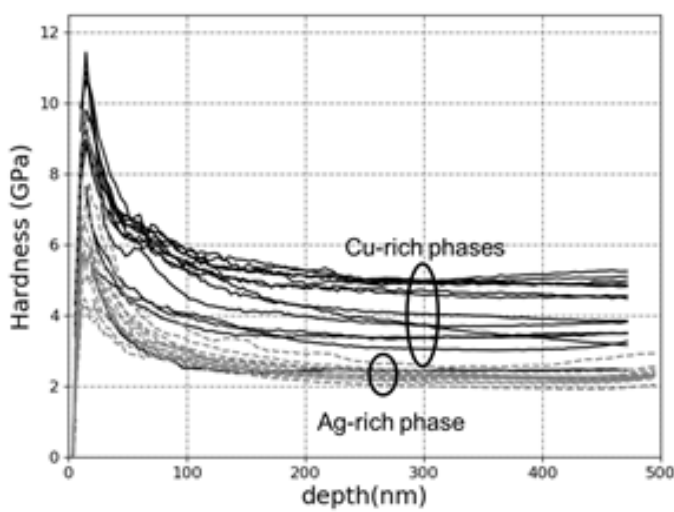

Fig. 9. Electrical and mechanical data from 28 indents performed in both Ag- and Cu-rich phases. (a) Resistance and (b) Hardness evolutions with indentation depth. Hardness data were extracted from Oliver-Pharr model [26]. 

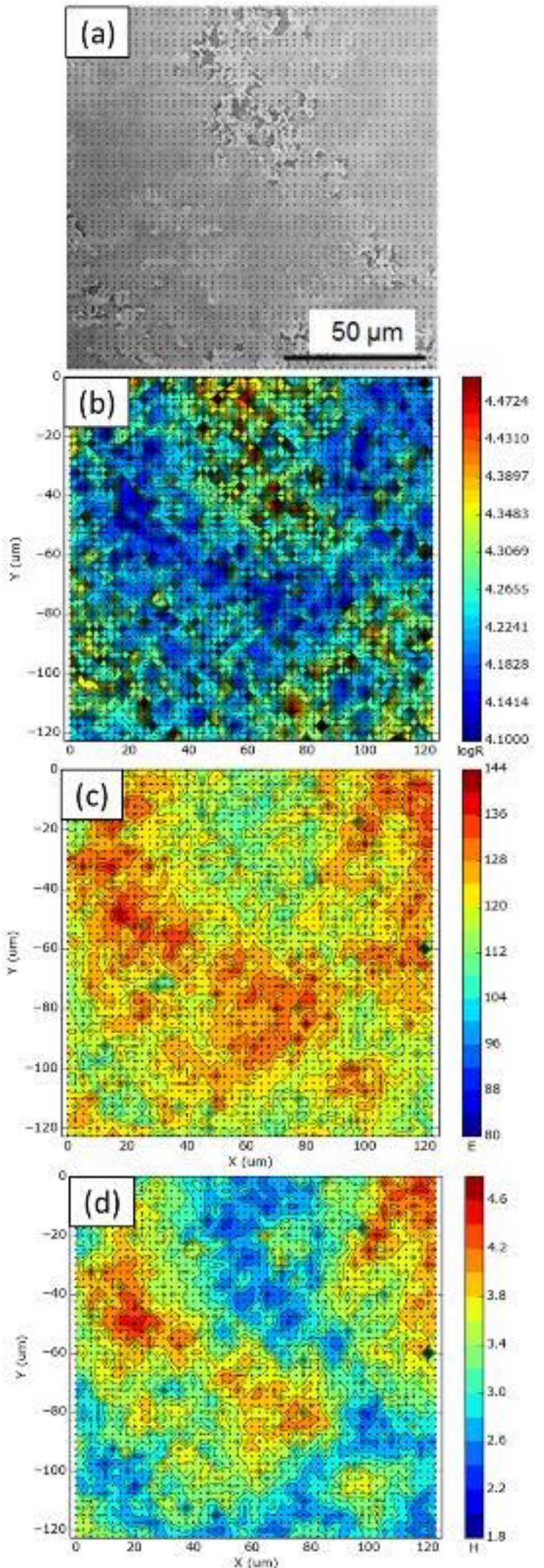

Fig. 10. Typical mapping of resistive and mechanical properties. (a) SEM micrograph of the domain after indentation (each dark dot is an indentation imprint). (b)-(c)-(d) Mapping of the electrical resistance (in log-scale), the elastic modulus and hardness, respectively. Mechanical magnitudes were extracted from Oliver-Pharr model [26].

\section{RESISTIVE-NANOINDENTATION ON NATIVE OXIDE LAYER}

The electro-mechanical behavior of two metals in contact often faces the presence of an oxide layer at their interface. Thus, the control of the electrical degradation of this oxide under a mechanical stress is critical [11,13]. The present set-up opens to the quantitative analysis of current leakage and/or breakdown phenomena. To do so, different materials have been studied: aluminum, copper and silicon (either natively-oxidized or capped by chemically-deposited oxides). In the present paper, for sake of clarity, focus is made on natively-oxidized aluminum [001] single crystal. The tests reported in the present paper were performed at room atmosphere. The alumina thickness was estimated to be $6-9 \mathrm{~nm}$ by X-Ray reflectometry. Representative resistance-vs-depth curves for different polarizations are shown in Fig. 11. First it can be seen that the contact resistance depends strongly on the applied voltage. This non-linearity of the electrical contact is confirmed by the current-voltage characteristics monitored at different penetration depths (Fig. 12).

In terms of depth-dependence, the trends are drastically different for large or small applied voltages. Under large voltages $(5$ and $10 \mathrm{~V})$, the resistance decreases the same way as for gold indentation (Fig. 4): at first order, contact resistance decreases as the reciprocal of the penetration depth. In contrast, at low voltages ( 0.5 and $2 \mathrm{~V})$, large instabilities (up and down) are observed. This low/large voltage discrepancy can be first explained by the electrical breakdown of the oxide. According to the approach proposed by Gloos et al. [36], the breakdown voltage of this alumina layer can be estimated to be $2.2 \mathrm{~V}(+/-0.6 \mathrm{~V})$. This value is in agreement with our experimental transition voltage (between 2 and $5 \mathrm{~V}$ ): beyond this polarization threshold, the oxide conductivity is large enough to make it transparent to electronic transport. It is to be noted that the mechanical failure of the oxide (detected by steep depth rises during indentation) is not sufficient to explain resistance drops: for the same test conditions (voltage, environment,...), an oxide crack can go along with a resistance drop (Fig. 13) or can occur without any resistance change (Fig. 14). This observation is in agreement with [11] and [13] on the $\mathrm{Al}_{2} \mathrm{O}_{3} / \mathrm{Al}$ and $\mathrm{SnO}_{2} / \mathrm{Sn}$ systems, respectively.

However the behavior observed at low voltages (i.e. before dielectric breakdown) is not straightforward. The random resistance rises (highlighted by black arrows in Fig. 11) and drops are unexpected while the contact area continuously increases. Comparable behaviors have already been reported for instance by Bouchoucha et al [37] on copper-steel contacts at constant force. The resistance rises were attributed to oxide growth. However some characteristic magnitudes were drastically different from our experiments: (1) while their resistances were multiplied by a factor of 4 , our resistance changes covered several orders of magnitude and (2) the time constant of their resistance variations were two orders of magnitude slower than in our case. We propose to explain these up and down instabilities from electrochemical processes occurring within the oxide.

As a solid electrolyte, alumina ensures electrical conduction through ionic processes only, meaning that 
conduction is essentially due to oxygen vacancy transport [38]. In the present experiment, oxygen vacancy mobility is highly promoted by local electromigration [2] and mechanical deformation. The electrochemical reactions involved at the diamond-tip/alumina and the alumina/aluminum interfaces are given by equations (2) (oxygen vacancy reduction) and (3) (oxygen production), respectively.

$$
\begin{gathered}
\frac{1}{2} O_{2}+V_{o}^{\infty 0}+2 e^{-} \rightarrow O_{o}^{X} \\
O_{O}^{X} \rightarrow \frac{1}{2} O_{2}+V_{O}^{\infty 0}+2 e^{-}
\end{gathered}
$$

These two reactions describe two competing trends in terms of resistance evolution. As the experiments are performed at room atmosphere, oxygen supply is fast enough to promote the first reaction at the diamond/alumina interface, thus pumping oxygen vacancies through the oxide and finally reducing the overall resistance. On the contrary, the second reaction describes the oxide growth at the second alumina/aluminum interface, thus increasing the overall resistance. These antagonistic trends can clearly explain the observed resistance instabilities at low voltages. This explanation is in agreement with the experiments performed under different relative humidity environment (not shown here [39]).

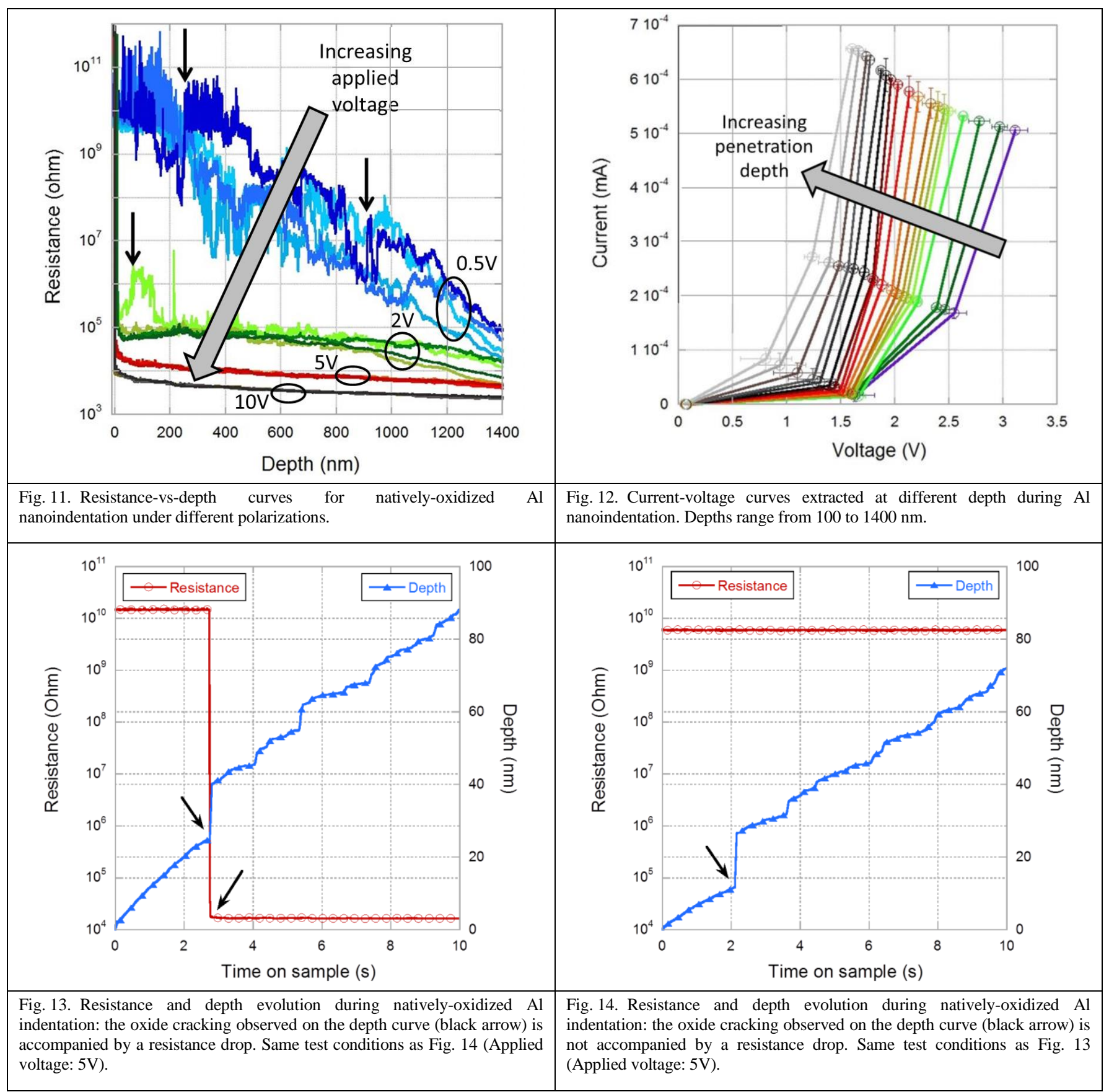




\section{CONCLUSION}

An experimental set-up dedicated to the coupling of local electrical and mechanical characterisations is presented. This set-up combines a nanoindentation head to fine electrical measurements in-situ in a scanning electron microscope. The experimental performances of the set-up (precision and sensitivity) are illustrated on both oxide-free and oxidized metals. First the ability to monitor quantitatively the contact area all along a nanoindentation test is demonstrated. Then a two-domain metallic system is characterized through either individual indents on each domain or large-scale mapping. Finally the electrical behavior of a native oxide is analyzed and described on the basis of dielectric breakdown and electrochemical processes. The prospects for further experiments are wide. For instance, this set-up can be applied to the characterisation of small-scale piezoelectric structures, or to the monitoring of permittivity transients induced by mechanical loads.

\section{ACKNOWLEDGMENT}

This work has been performed with the financial support of the Centre of Excellence of Multifunctional Architectured Materials "CEMAM" $\mathrm{n}^{\circ}$ ANR-10-LABX44-01. The CEMAM program is funded by the French Agence Nationale de la Recherche (ANR).

The authors thank the technical team of SIMaP lab (B. Mallery, S. Massucci, N. Vidal) for its support, the CMTC platform (physico-chemical characterization platform of Grenoble INP), as well as members of CSI/Scientec company (Les Ulis, France) for their support for the functionalization of the nanoindentation head: L. Pacheco, A. Lecoguiec and S. Poulet.

\section{REFERENCES}

[1] R. Holm. "Electrics Contacts, Theory and Applications", Springer, 2000.

[2] M. Braunovic, V.V. Konchits, N.K. Myshkin, "Electrical Contacts, Fundamental, Applications and Technology", "BRAU", CRC Press, 2007.

[3] G. Binnig, C. F. Quate, and Ch. Gerber, "Atomic Force Microscope", Phys. Rev. Lett. 56, 930, 1986.

[4] W. Vandervorst, M.Meuris, European patent 466274, 1992

[5] P.Eyben, W.Vandervorst, D.Alvarez, M.Xu, and M.Fouchier, "Probing Semiconducteurs Technology and Devices with Scanning Spreading Resistance Microscopy", in "Scanning Probe Microscopy Electrical and Electromechanical Phenomena at the $\mathrm{Na}$ Probing", Springer, 2007

[6] H. Nili, K. Kalantar-Zadeh, M. Bhaskaran, S. Sriram, "In situ nanoindentation: Probing nanoscale multifunctionality", Prog Mater Sci. 58, 2013.

[7] D. R. Clarke, M. Kroll, P. D. Kirchner, R. F. Cook, B. J. Hockey, "Amorphization and Conductivity of Silicon and Germanium Induced by Indentation" Phys. Rev. Lett. 60 2156-2159, 1988.

[8] G. M. Pharr, W. C. Oliver, R. F. Cook, P. D. Kirchner, M. Kroll, T. R. Dinger, "Electrical resistance of metallic contacts on silicon and germanium during indentation”, J. Mater. Res. 7 961-972, 1992.
[9] S. Ruffell, J. E. Bradby, J. S. Williams, O. L. Warren, "An in situ electrical measurement technique via a conducting diamond tip for nanoindentation in silicon", J. Mater. Res. 22 578-585, 2007.

[10] J. B. Pethica, D. Tabor, "Contact of characterised metal surfaces at very low loads: Deformation and adhesion", Surf. Sci. 89 189-190, 1979.

[11] D. D. Stauffer, R. C. Major, D. Vodnick, J. H. Thomas, J. Parkern, M. Manno, C. Leighton, W. W. Gerberich, "Plastic response of the native oxide on $\mathrm{Cr}$ and $\mathrm{Al}$ thin films from in situ conductive nanoindentation", J. Mater. Res. 27 685-693, 2012.

[12] H. H. Nguyen, P. J. Wei, J. F. Lin, "Electric contact resistance for monitoring nanoindentation-induced delamination", Adv. Nat. Sci.: Nanosci. Nanotechnol. 2 015007-1-4, 2011.

[13] T. Shimizu, T. Horie, N. Watanabe, J. Miyawaki, S. Fujii, Y. Yamagata, T. Kondo, M. Onuma, "The investigation of electrical contacts using newly designed nano-indentation manipulator in scanning electron microscope", Proc. 60th IEEE Holm Conf. Elect. Cont. 403-406, 2014.

[14] P. Y. Duvivier, V. Mandrillon, K. Inal, C. Dieppedale, S. DeldonMartoscia, J. P. Polizzi, "Investigation of the Electrical Resistance of $\mathrm{Au} / \mathrm{Au}$ Thin Film Micro Contacts", Proc. 56th IEEE Holm Conf. Elect. Cont. 58-64 Time Dependence, 2010.

[15] B. Arrazat, P. Y. Duvivier, V. Mandrillon, K. Inal, "Discrete Analysis of Gold Surface Asperities Deformation under Spherical Nano-Indentation Towards Electrical Contact Resistance Calculation", Proc. 57th IEEE Holm Conf. Elect. Cont.1-8, 2011.

[16] L. Fang, C. L. Muhlstein, J. G. Collins, A. L. Romasco, L. H. Friedman, "Continuous electrical in situ contact area measurement during instrumented indentation", J. Mater. Res. 23 2480-2485, 2008.

[17] D. J. Sprouster, S. Ruffel, J. E. Bradby, D. D. Stauffer, R. C. Major, O. L. Warren, J. S. Williams, "Quantitative electromechanical characterization of materials using conductive ceramic tips", Acta Mater. 71 153-163, 2014.

[18] Rabe R, Breguet JM, Schwaller P, Stauss S, Haug FJ, Patscheider $\mathrm{J}$, et al, "Observation of fracture and plastic deformation during indentation and scratching inside the scanning electron microscope", Thin Solid Films, 469-470:206-13, 2004.

[19] Wall MA, Dahmen U, "Development on an in situ nanoindentation specimen holder for the high voltage electron microscope", Microsc Microanal ; 3:593-4, 1997.

[20] Sridhar S, Giannakopoulos AE, Suresh S, Ramamurty U. "Electrical response during indentation of piezoelectric materials: a new method for material characterization”, J Appl Phys, 85:380-7, 1999.

[21] Rar A, Pharr GM, Oliver WC, Karapetian E, Kalinin SV. "Piezoelectric nanoindentation", J Mater Res ;21:552-6, 2006

[22] Schuh CA, Packard CE, Lund AC. "Nanoindentation and contactmode imaging at high temperatures", J Mater Res; 21:725-36, 2006.

[23] W. C. Oliver and G. M. Pharr, "Measurement of hardness and elastic modulus by instrumented indentation: Advances in understanding and refinements to methodology", J. Mater. Res., Vol. 19, No. 1, Jan 2004.

[24] L. Maniguet, F.Roussel, R.Martin, E.Djurado, M.C.steil, E.Bichaud, A.LeGo, M. Holzinger, S.Cosnier, J.M.Chaix, and C.Carry, "Fuel cells and ceramic-characterizing real-worlds sample with a fesem ready for challenges", Microscopy and Analysis, 21:47, 2015.

[25] F. Houzé, R.Meyer, O.Schneegans, and L.Boyer, "Imaging the local electrical properties of metal surfaces by atomic force microscopy with conducting probes", Applied Physics Letters, 69:19751977, 1996.

[26] W. C. Oliver, G. M. Pharr, "An improved technique for determining hardness and elastic modulus using load and displacement sensing indentation experiments", J. Mater. Res.7 1564-1582, 1992.

[27] J. L. Loubet, M. Bauer, A. Tonck, S. Bec, B. Gauthier-Manuel, "Mechanical Properties and Deformation Behavior of Materials Having Ultra-Fine Microstructures : Nanoexperiments with a surface force apparatus", in: M. Nastasi, D. M. Parkin, H. Gleiter (Eds.), "Mechanical Properties and Deformation Behavior of Materials Having Ultra-Fine Microstructures", Kluwer Academic Publisher 429-447, 1993. 
[28] S.Comby-Dassonneville, F. Volpi, G. Parry, D. Pellerin, M. Verdier, "Resistive-nanoindentation: contact area monitoring by real-time electrical contact resistance measurement", MRS Communications 2019, accepted.

[29] Y. Sharvin, "A possible method for studying fermi surfaces", Soviet Physics Jetp-Ussr, 21(3):655656, 1965.

[30] J. Barjon, N. Habka, C. Mer, F. Jomard, J. Chevallier, P. Bergonzo, "Resistivity of boron doped diamond", Phys. Status Solidi RRL 3, No. 6, 202-204, 2009.

[31] M. Kapilashrami, G. Conti, I. Zegkinoglou, S. Nemšák, C. S. Conlon, T. Törndahl, V. Fjällström, J. Lischner, Steven G. Louie, R. J. Hamers, L. Zhang, J.-H. Guo, C. S. Fadley, and F. J. Himpsel, "Boron Doped diamond films as electron donors in photovoltaics: An X-ray absorption and hard X-ray photoemission study”, Journal of Applied Physics 116, 143702, 2014.

[32] A. Kardakova, A. Shishkin, A. Semenov, G. N. Goltsman, S. Ryabchun, et al.. "Relaxation of the resistive superconducting state in boron-doped diamond films", Physical Review B : Condensed mat-ter and materials physics, American Physical Society, 93 (6), pp.064506, 2016

[33] J. A.Greenwood, "Constriction resistance and the real area of contact”, Journal of Applied Physics, 17:16211631, 1966.
[34] S.K. Khera, RN. Tank, PKK. Nayar, "Phase Equilibrium Studies in Solid Copper-Silver-Palladium Alloys at Elevated Temperatures" Trans. Indian I Metals, 105-107, 1972

[35] O. Kubaschewski, E. Semenevo et S. Ilyenko, "Ag-Cu-Pd", in G. Effenberg, S. Ilyenko (ed.), "Noble Metal Systems. Selected Systems from Ag-Al-Zn to Rh-Ru-Sc · Introduction", LandoltBörnstein - Group IV Physical Chemistry 11B, SpringerMaterials, 2006

[36] K. Gloos, P.J.Koppinen, and J.P.Pekola. "Properties of native ultra thin aluminium oxide tunnel barriers", Journal of Physics: Condensed Matter, 15:17331746, 2003.

[37] A. Bouchoucha, H.Zaidi, E.K.Kadiri, and D.Paulmier. "Influence of electric eldson tribological behaviour of electrodynamical copper/steel contacts", Wear, 203-204:434441,1997.

[38] C. Desportes, P. Fabry, M. Duclot, J. Fouletier, A. Hammou, M. Kleitz, E. Siebert, J-L. Souquet, "Electrochimie des solides", Presses Universitaires de Grenoble, 1994.

[39] https://tel.archives-ouvertes.fr/tel-01897366 